\title{
The politically engaged scientist
}

The appetite for political engagement among scientists across the United States has increased since the 2016 election. If well channeled and sustained, this would be a positive development that could last beyond the current administration's tenure.

These can feel like dark days for science in America. Drastic cuts have been proposed to biomedical research budgets, environmental regulatory bodies are being weakened, immigrant members of the scientific community feel insecure, and there are fears that certain government scientists may be silenced. The very bedrock of scientific thinking - reason, and the attempt to distinguish fact from artifact-is losing prominence and respect in the public discourse. Many of these developments are not entirely new; they did not appear sui generis in January 2017. Nevertheless, it is difficult to avoid the impression that science is increasingly under attack.

If there is a positive side to this state of affairs, it lies in the realization of many scientists that we must engage more with the nation's civic and political life. In Nature Methods' contact with the scientific community over recent months, it has become clear that this is not far from the minds of many authors and readers.

The experience of science advocacy organizations also bears this out. Since January of this year, the Center for Science and Democracy (part of the Union for Concerned Scientists) has seen more sign ups than is typical by scientists volunteering their time and services, says research director Gretchen Goldman. Since January, the Center has also been offering opportunities for scientists seeking an even higher level of engagement. Separately, the nonprofit political action committee 314 Action has reportedly been overwhelmed by the interest shown in their 'candidate training' for scientists who are considering running for office. The 2016 election has apparently created a new zeal for science advocacy. This April there will be not one, but two, science-related marches (the March for Science and the People's Climate March).

This reflects a larger trend of political engagement by many groups, but science can be a particularly widereaching platform. It is not inherently partisan; science is a powerful system of knowledge generation, but it does not in itself take political sides. Its fruits (and failures) have the potential to apply to Republicans, Democrats, and independents alike. Further, in spite of the discouraging lack of scientific thinking among some of the country's highest officials, science still does draw respect and interest from citizens. As
Jonathan Flynn - coordinator of BrainSTEM, a multiinstitutional outreach effort teaching neuroscience to disadvantaged students in Houston-puts it, "most people still want science on their side."

Some scientists may feel that their strengths lie in the laboratory rather than in the community or on the political stage. Even among those who cannot ignore an instinct for action, many express feeling overwhelmed by their unfamiliarity of the process. Yet political engagement can happen at many levels. Certainly only a small minority of scientists will consider running for any elected office, let alone congressional office. For the rest of us, political and civic activity must come in smaller doses.

Perhaps the one theme encountered most frequently, both from scientists expressing a wish for greater engagement and from advocates hoping to aid this process, is the need to make science-what its goals are, what scientists actually do, how it matters for the larger community-more visible locally. This can take many forms: sharing one's excitement for a recent discovery in a local newspaper, for example, organizing a science-themed event, or teaching what one knows to local children. In a commendable example of this, scientists at Janelia, near Washington, DC but also close to rural districts of Virginia and West Virginia, have begun teaching computer programming to local children and are organizing to extend this to rural communities.

Also, as pointed out by Shaughnessy Naughton, founder of 314 Action, scientists would do well not only to see themselves as advisors or teachers, but also to inform themselves about the civic process. Presidential elections may take place once every four years; but other elections, including local and state elections, are much more frequent. It isn't enough to communicate with political representatives about scientific issues one cares about; it is also an imperative, obvious as it may sound, to vote.

Small, local actions like these, at the level that is possible at a given time for a given person, need not deeply sap scientists' time and energy. Yet such actions are likely, in the long term, to have an impact on support for science in the larger community. They could lay the groundwork for a more informed population and perhaps even a more equitable nation well beyond the Trump years. 